\title{
A CRISE EM PERSPECTIVA: 1929 E 2008
}

\author{
FREDERICO MAZZUCCHELLI ${ }^{1}$
}

\section{RESUMO}

No contexto de elevada incerteza decorrente da crise econômica mundial, é inevitável que surjam comparações entre o momento atual e a experiência dramática da Grande Depressão, que subverteu o mundo entre 1929 e 1933. Mas, apesar das perdas financeiras e da desaceleração da economia, a disposição para a intervenção estatal é hoje um elemento determinante que diferencia nitidamente as iniciativas da política econômica. Este é um fator decisivo que projeta um futuro menos sombrio para a evolução da crise atual.

PALAVRAS-CHAVE: crise econômica; crise de 1929; intervenção do

Estado; capitalismo.

\section{SUMMARY}

In the current context of high uncertainty, many parallels have been traced between the economic crisis of 2008 and the Great Depression, that stirred the world between 1929 e 1933. However, despite the financial losses that recently occurred, the disposition for state intervention in our days is much higher and thus an important element in the formulation of economic policies. This is a difference that suggests a less catastrophic outcome to the current crisis.

KEYWORDS: economic crisis; crisis of 1929; state intervention; capitalism.

[1] Sou especialmente grato a Marcos Antonio Macedo Cintra pela iniciativa em publicar estas páginas, inicialmente destinadas a meus alunos. Coube a Marcos a concepção e confecção das tabelas, a cuidadosa elaboração das referências bibliográficas, bem como as precisas e detalhadas informações sobre as transformações recentes do sistema financeiro mundial, a extensão da crise atual e as reações dos governos. Apenas sua exagerada modéstia impediu que este artigo fosse assinado em co-autoria.
A profundidade da crise que assola parte significativa do sistema financeiro mundial provocará, certamente, impactos sobre a evolução dos agregados econômicos reais (produção, investimento, emprego etc.). Já se torna evidente que a economia mundial ingressou em uma fase de desaceleração ou recessão, cujo desfecho é ainda desconhecido. Segundo as projeções do Fundo Monetário Internacional (FMI), a economia mundial deverá desacelerar do patamar de 5\% ao ano, entre 2006 e 2007, para 2,2\% em 2009 (ver Tabela 1). Nesse último ano, as economias avançadas deverão apresentar queda no Produto Interno Bruto (PIB) de 0,3\%. A média da taxa de crescimento dos países em desenvolvimento cairá de $8 \%$,em 2007, para 5,1\%. O dinamismo do comércio internacional também aponta para um acentuado arrefecimento, caindo de 7,2\%, em 2007, para 2,1\%, em 2009. É inevitável, neste contexto de elevada incerteza, que surjam comparações entre o momento atual e a experiência dramática da Grande Depressão, que subverteu o mundo, sobretudo entre 1929 e 1933. 


\begin{tabular}{|c|c|c|c|c|c|c|c|}
\hline & 2003 & 2004 & 2005 & 2006 & 2007 & 2008(a) & $2009(a)$ \\
\hline \multicolumn{8}{|l|}{ Produto Interno Bruto Real } \\
\hline Mundo & 3,6 & 4,9 & 4,5 & 5,1 & 5,0 & 3,7 & 2,2 \\
\hline Economias avançadas & 1,9 & 3,2 & 2,6 & 3,0 & 2,6 & 1,4 & $-0,3$ \\
\hline Estados Unidos & 2,5 & 3,6 & 2,9 & 2,8 & 2,0 & 1,4 & $-0,7$ \\
\hline Área do Euro & 0,8 & 2,1 & 1,6 & 2,8 & 2,6 & 1,2 & $-0,5$ \\
\hline Alemanha & $-0,2$ & 1,2 & 0,8 & 3,0 & 2,5 & 1,7 & $-0,8$ \\
\hline Japão & 1,4 & 2,7 & 1,9 & 2,4 & 2,1 & 0,5 & $-0,2$ \\
\hline Reino Unido & 2,8 & 2,8 & 2,1 & 2,8 & 3,0 & 0,8 & $-1,3$ \\
\hline \multicolumn{8}{|l|}{ Países emergentes e } \\
\hline em desenvolvimento & 6,3 & 7,5 & 7,1 & 7,9 & 8,0 & 6,6 & 5,1 \\
\hline África & 5,4 & 6,5 & 5,8 & 6,1 & 6,1 & 5,2 & 4,7 \\
\hline Europa Central e do Leste & 4,8 & 6,9 & 6,1 & 6,7 & 5,7 & 4,2 & 2,5 \\
\hline \multicolumn{8}{|l|}{ Comunidade de Estados } \\
\hline Independentes & 7,8 & 8,2 & 6,8 & 8,2 & 8,6 & 6,9 & 3,2 \\
\hline Ásia em Desenvolvimento & 8,2 & 8,6 & 9,0 & 9,8 & 10,0 & 8,3 & 7,1 \\
\hline Oriente Médio & 7,1 & 5,8 & 5,7 & 5,7 & 6,0 & 6,1 & 5,3 \\
\hline América Latina & 2,2 & 6,1 & 4,7 & 5,5 & 5,6 & 4,5 & 2,5 \\
\hline Brasil & 1,1 & 5,7 & 3,2 & 3,8 & 5,4 & 5,2 & 3,0 \\
\hline $\begin{array}{l}\text { Volume do comércio mun } \\
\text { (bens e servições) }\end{array}$ & 5,4 & 10,4 & 7,5 & 9,4 & 7,2 & 4,6 & 2,1 \\
\hline
\end{tabular}

Fonte: FMI, World Economic Outlook Update, Washington, D.C., November 6, 2008. Notas: (a) Projeções.

Seguramente, o peso da riqueza financeira em relação ao produto, a sofisticação (e opacidade) das operações financeiras e a interligação entre os vários segmentos dos mercados em escala global são hoje infinitamente maiores do que no final da década de 1920. A dimensão recente alcançada pela riqueza financeira (US \$ 229,7 trilhões em dezembro de 2007, mais de quatro vezes superior ao PIB mundial ver Tabela 2) e e escala real ou nocional das perdas incorridas sugerem que estamos diante de um processo monumental de desvalorização de ativos, muitas vezes superior ao que se assistiu há quase oitenta anos. De acordo com a Federação Mundial das Bolsas de Valores, a desvalorização da riqueza acionária global somou US $\$ 29,5$ trilhões entre outubro de 2007 e outubro de 2008. Segundo o Banco da Inglaterra, os bancos ingleses registraram perdas com marcação a mercado da ordem de $£$ 10 bilhões ao mês, entre maio e outubro de 2008 , somando $£$ 122, 6 bilhões. Nos Estados Unidos, Reino Unido e área do euro, as perdas com marcação a mercado sobre ativos financeiros por bancos podem atingir US $\$ 2,8$ trilhões. A conclusão que daí poderia advir é que o curso dos acontecimentos será,em conseqüência, mais dramático e doloroso do que em 1929-1933. 
[2] Em 30 de setembro, a Irlanda concedeu garantia integral aos depósitos bancários por um período de dois anos. Temendo corridas bancárias, o governo britânico anunciou, no dia seguinte, a ampliação do limite da garantia aos depósitos para $£_{5}$ mil. Em seguida, os governos da Alemanha e Dinamarca concederam garantia integral aos depósitos bancários, levando a União Européia a aumentar, no dia 7 de outubro, o limite mínimo de garantia de $€ 20$ mil para $€ 50$ mil. Em 14 de outubro, a agência americana, Federal Deposit Insurance Company (FDIC), garantiu por três anos as novas operações dos bancos e das instituições de poupança e holding companies incluindo notas promissórias, commercial papers, empréstimos interbancários. Simultaneamente, tornou ilimitada, até abril de 2009 , a garantia do FDIC aos depósitos bancários não remunerados para evitar qualquer prejuízo, sobretudo, aos pequenos depositantes.

[3] O governo americano adquiriu US $\$ 25$ bilhões em ações preferenciais do Bank of America, do JP Morgan/Chase, Citigroup e do Wells Fargo; US $\$ 10$ bilhões dos ex-bancos de investimento Goldman Sachs e Morgan Stanley; US $\$ 3$ bilhões do Bank of New York Mellon; US $\$ 2$ bilhões do State Street. O restante (US $\$ 125$ bilhões) foi distribuído entre instituições de poupança $e$ aos bancos menores, regionais e locais, com dificuldades em levantar capital.

[4] Em 29 de outubro de 2008,0 Federal Reserve disponibilizou US\$ 30 bilhões, por meio de swap de moedas, para cada um dos bancos centrais do Brasil, Cingapura, Coréia do Sul e México, a fim de ampliar a liquidez em dólar nos mercados emergentes (acordo válido por seis meses, até abril de 2008 [ver <www.federalreserve.gov/newsevents/press/ monetary/20081029b.htm>, acessado em 23/11/2008]).
Felizmente, tal conclusão não se sustenta. É necessário assinalar, em primeiro lugar, que em face da eclosão da crise a intervenção dos governos foi ampla e imediata. $O$ credo liberal e a panacéia dos mercados "eficientes" ou "auto-regulados" foram sumariamente abandonados e o Estado assumiu, com maior (Inglaterra) ou menor (Estados Unidos) grau de acerto, a responsabilidade pela defesa das instituições financeiras, pela provisão da liquidez, pela garantia integral dos depósitos ${ }^{2}$, pela redução das taxas de juros básicas e pela tentativa de evitar o aprofundamento da contração do crédito. Destaca-se a decisão de o governo americano disponibilizar US \$2,25 trilhões, sendo US $\$ 1,5$ trilhão para garantir novas dívidas emitidas pelos bancos, US $\$$ 500 bilhões para garantir os depósitos nos fundos mútuos e US $\$ 250$ bilhões para capitalizar os grandes bancos3. O Banco Central americano (Federal Reserve) aumentou ainda para US $\$ 900$ bilhões seus acordos de troca de moedas com dez bancos centrais (Austrália, Canadá, Dinamarca, Inglaterra, Nova Zelândia, Japão, Noruega, Suécia, Suíça e Banco Central Europeu) para ampliar a liquidez em dólares nos principais centros monetários ${ }^{4}$. Os países da União Européia (Alemanha, França, Holanda, Espanha, Áustria, Portugal, Reino Unido e Suécia) e a Noruega, por sua vez, disponibilizaram US $\$ 2,75$ trilhões para garantir as operações interbancárias. Além disso, a Itália anunciou disponibilizar "o quanto for necessário" e a Polônia sinalizou plano semelhante.

Sem a pronta e contínua injeção dos recursos públicos o colapso teria sido total, diante da absoluta preferência pela liquidez, com fuga desenfreada para os títulos da dívida pública, sobretudo americanos. A ação dos governos, tipicamente keynesiana, tem sido a de buscar a restauração do circuito do crédito-gasto-renda, nem que para tanto seja necessário estatizar (ainda que parcial e temporariamente) parcela significativa do sistema financeiro (ver Quadro 1).

Umaintervençãovigorosa, como a queocorreu em 2007 e 2008 , seria impensável em 1929. Não se deve esquecer que o conventional wisdom nos anos 1920 era determinado pelas regras do padrão-ouro. Em particular, as ações expansionistas (sobretudo fiscais) eram vistas com suspeição por alimentar a inflação e precipitar, dessa forma, a desvalorização cambial. Câmbio fixo e orçamentos equilibrados conformavam uma unidade indissociável. A defesa do câmbio era o objetivo supremo, que condicionava a política monetária e, na prática, anulava a política fiscal. Os Estados Unidos retornaram ao padrão-ouro em 1919, a Alemanha em 1923, a Inglaterra em 1925, e a França, de fato, em 1926. Quando da eclosão da turbulência de 1929, Hoover em nenhum momento cogitou abandonar o padrão-ouro. Brüning (que comandou o gabinete alemão a partir de março de 1930) procurou combater a recessão com a deflação. A França, desde o Franc Poincaré, cultivou sua devoção ao ouro até 
setembro de 1936 e, da mesma forma, insistiu na tentativa vã de impor a deflação como remédio para a depressão. Mesmo após a desvalorização da libra em setembro de 1931, a Inglaterra, apesar de praticar uma política de cheap money, permaneceu circunscrita a uma política fiscal conservadora. Nem mesmo Roosevelt conseguiu se desvencilhar do dogma dos orçamentos equilibrados: em 1937, sua tentativa de "sanear" as finanças públicas redundou na "recessão na depressão” de 1938. Unicamente Hitler, desde 1933, praticou uma política deliberada de expansão dos gastos públicos. O outrora austero Hjalmar Schacht, que entre 1923 e 1930 foi o zeloso guardião da moeda alemã, garantiu sua recondução ao posto em 1933 apenas mediante o compromisso explícito, assumido com o Führer, de envolver diretamente o Reichbank no financiamento dos gastos do governo5.

A verdade, assim, é que com a exceção do experimento nazista, todos - à direita e à esquerda - professavam sua crença mítica nas virtudes das sound finances. Seria impensável, em 1930 ou 1931, que um economista escrevesse, poucos dias após ser laureado com o Prêmio Nobel, que em face da extensão da crise "não é hora de pensar no déficit" (Paul Krugman) 6 . Ao contrário da experiência traumática da Grande
[5] Mazzucchelli, Frederico. Os anos de chumbo: notas sobre a economia e a política internacional no entreguerras. Campinas: Editora Facamp, 2008 (no prelo).

[6] Krugman, Paul. "Não é hora de pensar no déficit". Folha de S.Paulo, 18/10/2008 (originalmente publicado no New York Times).

\section{TABELA 2}

Indicadores selecionados do tamanho dos mercados de capitais, 2007

\begin{tabular}{|c|c|c|c|c|c|c|c|c|c|c|}
\hline & \multirow[b]{2}{*}{ PIB } & \multirow{2}{*}{$\begin{array}{c}\text { Reservas } \\
\text { (a) }\end{array}$} & \multirow{2}{*}{$\begin{array}{l}\text { Capitali- } \\
\text { zação do } \\
\text { mercado } \\
\text { acionário }\end{array}$} & \multicolumn{3}{|c|}{ Dívidas (b) } & \multirow{2}{*}{$\begin{array}{c}\text { Ativos } \\
\text { Bancos } \\
\text { Comerciais }\end{array}$} & \multirow[b]{2}{*}{ Total (c) } & \multirow{2}{*}{$\begin{array}{l}\text { Total } \\
\text { em } \%\end{array}$} & \multirow{2}{*}{$\begin{array}{c}\text { Total em } \% \\
\text { do PIB }\end{array}$} \\
\hline & & & & Pública & Privada & Total & & & & \\
\hline Mundo & $54 \cdot 545,1$ & $6.448,0$ & $65.105,6$ & $28.632,1$ & $51.189,8$ & $79.821,9$ & $84.784,5$ & $229.712,0$ & 100,0 & 421,1 \\
\hline União Européia & $15.688,8$ & 279,7 & $14 \cdot 730,9$ & $8.788,0$ & $19.433,3$ & $28.221,3$ & $43 \cdot 146,3$ & $86.098,5$ & 37,5 & 548,8 \\
\hline Reino Unido & $2.765,4$ & 49,0 & $3.851,7$ & 913,5 & $2.931,2$ & $3.844,7$ & $11.052,5$ & $18.748,9$ & 8,2 & 678,0 \\
\hline Área do Euro & $12.202,6$ & 172,1 & $10.040,1$ & $7 \cdot 612,7$ & $15 \cdot 411,2$ & $23.023,8$ & $30.137,1$ & $63.461,4$ & 27,6 & 520,1 \\
\hline Alemanha & $3 \cdot 320,9$ & 44,3 & $2.105,2$ & $1.700,3$ & $3.905,1$ & $5.606,1$ & $6.492,7$ & $14.204,0$ & 6,2 & 427,7 \\
\hline França & $2.593,8$ & 45,7 & $2.737,1$ & $1.447,2$ & $2.919,6$ & $4 \cdot 366,8$ & $8.685,2$ & $15 \cdot 789,1$ & 6,9 & 608,7 \\
\hline Estados Unidos & $13.807,6$ & 59,5 & $19 \cdot 922,3$ & $6.594,0$ & $23.285,2$ & $29.879,3$ & $11.194,1$ & $60.995,7$ & 26,6 & 441,8 \\
\hline Japão & $4 \cdot 381,6$ & 952,8 & $4.663,8$ & $7.147,7$ & $2.069,8$ & $9.217,5$ & $7.839,4$ & $21.720,6$ & 9,5 & 495,7 \\
\hline Economias Emergentes & $17.281,7$ & $4 \cdot 910,1$ & $20.950,2$ & $4.908,4$ & $2.911,7$ & $7.820,1$ & $15.003,8$ & $43 \cdot 774,1$ & 19,1 & 253,3 \\
\hline Ásia & $7 \cdot 482,4$ & $2.988,2$ & $13.782,7$ & $2.556,4$ & $1.948,5$ & $4 \cdot 505,0$ & $9.382,3$ & $27.670,0$ & 12,0 & 369,8 \\
\hline América Latina & $3.608,5$ & 445,2 & $2.292,2$ & $1.456,5$ & 628,4 & $2.084,9$ & $1.988,7$ & $6.365,8$ & 2,8 & 176,4 \\
\hline Europa & $3.527,20$ & 845,9 & $2.417,60$ & 766,7 & 173,5 & 940,2 & $1.820,20$ & $5.178,00$ & 2,3 & 146,8 \\
\hline
\end{tabular}

Fonte: World Federation of Exchanges; Bank of International Settlements; IMF, International Financial Statistics (IFS), World Economic Outlook databases as of September 25, 2008; 2003 Bureau van Dijk Electronic Publishing-Bankscope; Standard \& Poor's Emerging Markets Database.

Notas: (a) Exclui reservas em ouro; (b) Inclui bônus emitidos por governos, instituições financeiras e corporações no mercado financeiro internacional; (c) Soma da capitalização do mercado acionário, dívidas securitizadas e ativos dos bancos comerciais. 
[7] Para uma excelente descrição das operações especulativas durante os anos 1920, ver Galbraith, John K. 1929: o colapso da Bolsa (São Paulo: Pioneira, 1988 [1954]). Para as inovações financeiras recentes, ver, entre outros, Guttmann, Robert e Plihon, Dominique. Consumer debt at the center of finance-led capitalism (Paris, jan. 2008 [mimeo]); Kregel, Jan. "Minsky's cushions of safety: Systemic risk and the crisis in the U.S. subprime mortgage market" (Public Policy Brief, $\mathrm{n}^{\mathrm{O}}$ 93, The Levy Economics Institute of Bard College, jan. 2008. Disponível em <http:// www.levy.org/pubs/ppb_93.pdf , acessado em 23/11/2008); Freitas, M. Cristina P. de e Cintra, Marcos Antonio M. "Inflação e deflação de ativos a partir do mercado imobiliário americano" (Revista de Economia Política, v. 28, n 3 (111), São Paulo, Editora 34,jul.-set.2008 [Disponível em 〈www.rep.org.br〉, acessado em 24/11/2008]).

[8] A aprovação do Gramm-LeachBliley Financial Modernization Act (1999) consolidou a expansão dos grandes bancos para as atividades típicas de bancos de investimento (negociação de securities), administração de ativos e operação no mercado de seguros mediante a formação de uma holding financeira (financial holding companies), consolidando os chamados financial supermarkets ("supermercados de serviços financeiros"). Ver, entre outros, Braga, José Carlos S. e Cintra, M.A.M. "Finanças dolarizadas e capital financeiro: exasperação sob comando americano" (In: Fiori, José L. (org.). O poder americano. Petrópolis:Vozes, 2004,pp.253-307); Cintra, M. A. M. e Cagnin, Rafael F. "Evolução da estrutura e da dinâmica das finanças norte-americanas" (Econômica, v. 9, n² 2. Niterói: UFF, dez.2007, pp.89-131).

[9] Não se deve esquecer o que Schumpeter denominou como o "remédio caseiro" dos republicanos às crises: a elevação das tarifas, propagando a crise em âmbito mundial.Em junho de 1930 foi promulgada a Smoot-Hawley Tariff, que elevou as tarifas sobre os produtos importados para cerca de $45 \%$, nível mais elevado de proteção observado desde 1833 . Ver Walton, G. M. e Rockoff, H., History of the American economy. Cincinnati, Ohio: South-Western Thomson Learning, 2002, p. 224.
Depressão, a disposição para a intervenção estatal é hoje, portanto, um elemento determinante que diferencia nitidamente as iniciativas da política econômica. Este é um fator decisivo que projeta um futuro menos sombrio para a evolução da crise atual.

Existe, de outra parte, uma clara semelhança em relação à origem dos distúrbios que resultaram na Grande Depressão e os que estão por detrás da presente convulsão. Em ambos os casos a débâcle foi precedida pela fragilidade da regulação e pelo relaxamento na percepção dos riscos, o que redundou em uma febre especulativa de conseqüências desastrosas. A inevitável proliferação de operações financeiras de lastro duvidoso, alavancadas pela expansão desmesurada do crédito, é um traço comum dos dois momentos históricos7. No final da década de 1920 e início da de 1930, era ainda limitado o grau de regulação e controle exercido pelas autoridades monetárias sobre o conjunto dos sistemas financeiros. Nos Estados Unidos - o epicentro do terremoto de 1929-1933 - era destacada a proliferação de bancos de pequeno e médio porte, muitos deles fora da área de supervisão do Federal Reserve. Ao mesmo tempo, a inexistência de um "muro de contenção" entre os bancos comerciais e os bancos de investimento permitiu que os primeiros se envolvessem em operações de alto risco, comprometendo de modo temerário os recursos dos depositantes (fenômeno que voltaria a se repetir em 2007-2008)8.

As respostas iniciais à crise de 1929 (ao contrário das intervenções atuais) foram completamente insuficientes e desastradas: as ações de lender of last resort, do mesmo modo que as iniciativas no plano fiscal, eram incompatíveis com os mandamentos sagrados do padrão-ouro. $O$ resultado foi a propagação das quebras, a contração da produção e a explosão do desemprego 9 . O PIB nominal nos Estados Unidos caiu de US $\$ 103,7$ bilhões em 1929 para US \$ 56,4 bilhões em 1932, recuperando-se para US $\$ 101,3$ bilhões apenas em 1939 (ver Tabela 3). Entre 1930 e 1933 os Estados Unidos assistiram a três ondas de liquidação bancária que vitimaram nada menos que 11 mil bancos. Na Alemanha, a quebra do gigante Danat em julho de 1931, perante a impotência da intervenção do Reichbank, foi um ponto de inflexão decisivo no aprofundamento do desespero econômico que terminou por conduzir os nazistas ao poder. No início de 1933, havia na Alemanha 6 milhões de desempregados formais e cerca de 3 milhões de desempregados ocultos.

Tanto nos Estados Unidos como na Alemanha a superação dos desdobramentos mais profundos da crise passou pela imposição de critérios de regulação mais rígidos sobre o sistema financeiro. Se Roosevelt, empossado em março de 1933, alcançou um sucesso inegável em quebrar a espiral contracionista foi porque, desde o início, 


\begin{tabular}{|c|c|c|c|}
\hline Instituição & Data & País & País \\
\hline Fannie Mae & 07 set. & Estados Unidos & Estatizada - US\$ 100 bilhões \\
\hline Freddie Mac & o7 set. & Estados Unidos & Estatizada - US\$ 100 bilhões \\
\hline Lehman Brothers & 15 set. & Estados Unidos & Falência \\
\hline Merrill Lynch & 15 set. & Estados Unidos & Adquirida pelo Bank of America \\
\hline AIG (American Internacional Group) & 16 set. & Estados Unidos & Parcialmente estatizada (US $\$ 150$ bilhões) \\
\hline HBOS (Halifax Bank of Scotland) & 17 set. & Reino Unido & $\begin{array}{l}\text { Adquirida pelo Lloyds TSB (US } \$ 22 \text { bilhões), } \\
\text { depois recebeu ( } £ 11,5 \text { bilhões) }\end{array}$ \\
\hline Washington Mutual & 25 set. & Estados Unidos & Falência, seguida de venda para o JPMorgan/Chase \\
\hline Fortis & 28 set. & $\begin{array}{l}\text { Bélgica/Holanda/ } \\
\text { Luxemburgo }\end{array}$ & $\begin{array}{l}\text { Parcialmente estatizada }- \text { US } \$ 47,7 \text { bilhões } \\
\text { ( } 49 \% \text { das ações) }\end{array}$ \\
\hline Bradford \& Bingley & 29 set. & Reino Unido & Estatizada (de hipotecas e créditos imobiliários) \\
\hline Wachovia & 29 set. & Estados Unidos & Adquirida pelo Wells Fargo \\
\hline Dexia & 30 set. & Bélgica e França & Estatizada (US $\$ 9,2$ bilhões) \\
\hline Glitnir & 29 set. & Islândia & Estatizada ( $75 \%$ das ações) \\
\hline Hypo Real Estate & o6 out. & Alemanha & $\begin{array}{l}\text { Socorrido pelo governo e consórcio de bancos } \\
\text { (US } \$ 69 \text { bilhões) }\end{array}$ \\
\hline Landsbanki & O7 out & Islândia & Estatizada \\
\hline Kaupthing Bank & lo out. & Islândia & Estatizada \\
\hline Yamato Life Insurance & 10 out. & Japão & Falência (companhia de seguro de vida) \\
\hline Royal Bank of Scotland & 13 out. & Reino Unido & Parcialmente estatizada (£2o bilhões) \\
\hline Lloyds TSB & 13 out. & Reino Unido & Parcialmente estatizada ( $£ 5,5$ bilhões) \\
\hline UBS & 16 out. & Suíça & $\begin{array}{l}\text { Parcialmente estatizada (recebeu US } \$ 5,2 \text { bilhões } \\
\text { e transferiu US } \$ 60 \text { bilhões dos ativos podres para } \\
\text { a autoridade monetária) }\end{array}$ \\
\hline ING & 19 out. & Holanda & Parcialmente estatizada (10 bilhões) \\
\hline National City Corp. & 24 out. & Estados Unidos & $\begin{array}{l}\text { Falência, seguida de venda para o PNC Financial } \\
\text { Services Group Inc. (US } \$ 5,2 \text { bilhões) }\end{array}$ \\
\hline Freedom Bank & 1 nov. & Estados Unidos & $\begin{array}{l}\text { Falência, os depósitos foram adquiridos pelo } \\
\text { Fith Third Bank (Michigan) }\end{array}$ \\
\hline Banco Português de Negócios (BPN) & 3 nov. & Portugal & Estatizada \\
\hline
\end{tabular}

Fonte: BBC News International; Financial Times; Wall Street Journal, The Economist, Grupo de Conjuntura da Fundap (Panorama e perspectiva das economias avançadas: sob o signo da crise, São Paulo, 5 de novembro de 2008), com informações disponíveis até o dia 10 de novembro. 


\begin{tabular}{|c|c|c|c|c|c|}
\hline & $\begin{array}{l}\text { PIB Real } \\
1932=100\end{array}$ & $\begin{array}{c}\text { Produção Industrial } \\
1932=100\end{array}$ & $\begin{array}{l}\text { Formação privada bruta de } \\
\text { capital fixo (US\$ bilhões) }\end{array}$ & $\begin{array}{l}\text { Consumo pessoal } \\
\text { (US\$ bilhões) }\end{array}$ & $\begin{array}{l}\text { PIB nominal } \\
\text { (US\$ bilhões) }\end{array}$ \\
\hline 1929 & 139,2 & 185,1 & 15,0 & 77,5 & 103,7 \\
\hline 1932 & 100,0 & 100,0 & 3,6 & 48,7 & 56,4 \\
\hline 1933 & 98,0 & 116,4 & 3,2 & 45,9 & 66,0 \\
\hline 1934 & 105,6 & 126,9 & 4,2 & 51,5 & 73,3 \\
\hline 1935 & 114,1 & 152,2 & 5,5 & 55,9 & 83,7 \\
\hline 1936 & 130,4 & 179,1 & 7,4 & 62,2 & 91,9 \\
\hline 1937 & 136,8 & 191,1 & 9,6 & 66,8 & 86,1 \\
\hline 1938 & 130,6 & 149,3 & 7,6 & 64,2 & 92,0 \\
\hline 1939 & 140,9 & 189,6 & 9,1 & 67,2 & 101,3 \\
\hline 1940 & 152,2 & 219,4 & 11,2 & 71,2 & 126,7 \\
\hline 1941 & 179,0 & 291,0 & 13,8 & 81,0 & 161,8 \\
\hline
\end{tabular}

[10] Mazzucchelli, op. cit.

[11] Ver Schacht, Hjalmar. Setenta e seis anos de minha vida. São Paulo: Editora 34, 1999, pp.367-455. promoveu o saneamento do setor bancário e estabeleceu, na seqüência, as bases da regulamentação do sistema financeiro por meio de um conjunto de dispositivos legais criados entre 1933 e 1934 (GlassSteagall Act II, Federal Deposit Insurance Corporation, Securities Exchange Act e Federal Savings and Loan Insurance Corporation). Além disso, o Emergency Banking Act de 9 de março de 1933 havia proibido a exportação de ouro e a Thomas Amendment de 19 de abril autorizara a flutuação do valor do dólar em relação ao ouro e, conseqüentemente, do dólar em relação às demais moedas. Os Estados Unidos abandonaram o padrão-ouro e o dólar entrou em uma progressiva trajetória de queda. A expectativa era de que, mesmo não sendo um instrumento suficiente para deslanchar a recuperação, a política monetária não deveria ser descartada enquanto ferramenta na luta pela reinflação. Com os juros libertos da "escravidão do câmbio fixo", a expansão do crédito bancário poderia irrigar a economia e estimular a alta dos preços. Com a desvalorização, os constrangimentos do câmbio fixo desapareceriam. A inflação tornarase bem-vinda e a política monetária estava doravante autorizada a assumir um perfil declaradamente expansivo ${ }^{10}$. Hitler e Schacht, de sua parte, converteram o sistema financeiro alemão em um braço operacional do Reichbank. O nazismo, ademais, impôs o controle absoluto sobre as transações em moeda estrangeira ${ }^{11}$. Nos dois casos, a disciplina sobre as finanças privadas foi essencial para que as economias se levantassem dos escombros da depressão. 
Da mesma forma, a superação da crise contemporânea deverá contemplar a implantação de um novo marco de regulação para o sistema financeiro. Como se sabe, foi nos anos 1970 e 1980 que o aparato regulatório da Golden Age (a chamada "repressão financeira") foi desmontado, em nome da imaginada eficiência das "finanças comandadas pelo mercado" ${ }^{12}$. Hoje, diante do descalabro e descontrole das operações financeiras que redundaram na atual crise, não há mais quem negue a necessidade imperiosa de reintroduzir padrões mais rígidos e rigorosos que disciplinem o funcionamento do sistema financeiro em âmbito nacional e internacional. Em particular, a regulamentação sobre o shadow financial system (bancos de investimento, fundos de investimento, hedge funds, seguradoras) - e a redefinição de suas relações com os bancos comerciais - é essencial para assegurar uma estabilidade mínima às economias capitalistas. A consciência de que é fundamental retomar a regulação sobre o mundo das finanças privadas é, assim - paralelamente à pronta decisão de utilizar os recursos públicos para mitigar a propagação da crise —, um fator essencial.É claro que a imposição de um novo marco regulatório para as finanças privadas não se dará em um piscar de olhos. Mas a percepção de sua urgência, ao mesmo tempo em que o Estado atua diretamente e sem ressalvas sobre a solvência do sistema financeiro, permite antever passada a tormenta - um funcionamento menos turbulento e tempestuoso para o mundo das finanças.

É necessário, ademais, atentar para um dado importante. No início dos anos 1930 a coordenação internacional tornara-se uma quimera. Era absolutamente impossível compatibilizar as ações do New Deal com as propostas nazistas, e ambas com o grupo do ouro liderado pela França ou com a área da libra comandada pela Inglaterra. $\mathrm{Na}$ década de 1930 a ordem internacional se estilhaçou e se formaram blocos de nações, com os países se envolvendo em ações essencialmente defensivas, o que redundou na escalada do protecionismo, nas desvalorizações competitivas e na busca de soluções autárquicas. A ausência de coordenação supranacional foi uma característica marcante dos anos 1930. Ela ensejou a tentativa de saídas particularistas para a crise, acirrou as rivalidades nacionais e deu livre curso às alternativas autoritárias. Felizmente, não é este o quadro que hoje se apresenta. Mesmo diante das naturais dificuldades em se alcançar soluções consensuais, existe um interesse comum entre os Estados Unidos, a União Européia, o Japão e a China em evitar a propagação da crise. Hoje, a ação coordenada (manifestada, por exemplo, na redução conjunta da taxa de juros ${ }^{13}$ tende a ser mais plausível - e factível - que as soluções particulares e isoladas (beggar thy neighbor) típicas dos anos 1930. No mesmo sentido, podem ser apreendidas as decisões encaminhadas no primeiro encontro dos países do $\mathrm{G}_{2} \mathrm{O}^{14}$
[12] Ver Belluzzo, Luiz Gonzaga M. "O declínio de Bretton Woods e a emergência dos mercados 'globalizados'". Revista Economia e Sociedade, $\mathrm{n}^{2}$ 4. Campinas: IE/Unicamp, 1995, pp. 11-20; Chesnais, François. "Introdução geral". In: Chesnais, F. (org.). A mundializaçãofinanceira: gênese, custos e riscos. São Paulo: Xamã Editora, 1998, pp.11-33.

[13] Em 8 de outubro, seis bancos centrais das principais economias avançadas - Estados Unidos, Canadá, área do euro, Reino Unido, Suécia e Suíça - realizaram uma ação coordenada de redução de 0,5 ponto percentual nas taxas de juros básicas.

[14] Contou com os membros do G7 (Estados Unidos, Japão, Alemanha, França, Reino Unido, Itália e Canadá) mais um grupo de nações emergentes que inclui Arábia Saudita, África do Sul, Argentina, Austrália, Brasil, China, Coréia do Sul, Índia, Indonésia, México, Rússia, Turquia, além dos representantes da União Européia e da Espanha. 
[15] Ver Cúpula sobre Mercados Financeiros e Economia Mundial, Declaração Final, Washington, 15 de novembro de 2008 (Declaration Summit on Financial Markets and the World Economy, November 15, 2008). para discutir a reforma da arquitetura financeira internacional, em 15 de novembro de 2008. A Cúpula sobre Mercados Financeiros e Economia Mundial (Declaração Final) sugeriu, entre outros pontos, "que as instituições internacionais devem elaborar recomendações a respeito de temas como a avaliação de ativos, a alavancagem, a capitalização, o provisionamento dos bancos e a remuneração dos executivos do setor financeiro para evitar que distorções exacerbem os movimentos cíclicos do mercado". Sugeriu ainda que

os supervisores devem colaborar para estabelecer comitês de inspeção para as maiores instituições financeiras multinacionais, como parte dos esforços para fortalecer a vigilância. Os maiores bancos globais devem se encontrar regularmente com esses comitês para discussões gerais sobre suas atividades e avaliação dos riscos enfrentados ${ }^{15}$.

Existe, por fim, uma diferença significativa entre as atuais atribulações econômicas e o contexto da Grande Depressão, que não pode ser desprezada. No início dos anos 1930, a proporção da população economicamente ativa empregada nas atividades agrícolas e extrativas era próxima a um quarto nos Estados Unidos, e a um terço na Alemanha. Com a Depressão, dada a maior sensibilidade dos preços agrícolas às variações da demanda, a renda real da população empregada no campo despencou. No caso dos Estados Unidos, a contração da renda real dos agricultores, entre 1929 e 1932, foi superior a $50 \%$, o que arrastou uma infinidade de bancos do Sul e do Meio-Oeste à falência. Somente por meio de uma ação tempestiva de defesa e sustentação dos preços agrícolas é que a profundidade e a duração da Depressão poderiam ser mitigadas. De fato, parcela relevante dos recursos públicos administrados pelo New Deal e pelos nazistas foi direcionada exatamente para a reversão do quadro devastador que se abateu sobre a agricultura. Hoje, esta questão nem sequer é colocada: nem a proporção da população empregada no campo é relevante, nem a participação da agricultura na criação da renda tem uma expressão econômica digna de maiores preocupações. É provável, entretanto, que o mercado imobiliário de hoje seja a agricultura de ontem: a dimensão da crise dos ativos relacionados às hipotecas de alto risco (subprime) ainda não é mensurável. É o próprio secretário do Tesouro americano quem afirma: "O problema real é que os bancos de todo o mundo fizeram empréstimos arriscados. [...] A coisa mais espantosa é a dimensão do problema". A cadeia de ativos "tóxicos" associados à especulação com imóveis ainda não foi desmontada, e é possível que o socorro da intervenção pública se torne aí tão intenso e prolongado quanto o foi para retirar a agricultura da vala da depressão nos anos 1930. 
As considerações anteriores indicam que não é previsível para a crise atual um desdobramento semelhante ao da Grande Depressão. Nada autoriza, contudo, uma perspectiva candidamente otimista. A extensão dos estragos é ainda desconhecida e o impacto sobre o setor produtivo seguramente será profundo ${ }^{16}$. Apenas a decidida intervenção do Estado tem evitado um descalabro de maiores proporções. A necessidade de retomar a regulamentação sobre o sistema financeiro é reconhecida, mas sua implementação certamente será precedida por desacordos substanciais e demandará tempo para ser efetivada. Da mesma forma, apesar de o ambiente internacional favorecer a busca de soluções cooperadas, não se deve imaginar que elas sejam simples e isentas de contradições, em particular no que diz respeito ao papel dos Estados Unidos e do dólar no contexto mundial.

Acrise atual representa, na verdade, uma derrota fragorosa do liberalismo irrefletido que contaminou os espíritos nos últimos trinta anos. A fé cega na capacidade de regulação dos mercados é um dogma que acompanha o capitalismo desde o seu nascimento. Desde a Fábula das abelhas, de Mandeville ("vícios privados, virtudes públicas")ㄱ, até os modelos de expectativas racionais de última geração, o suposto é sempre o mesmo: os mercados possuem uma racionalidade imanente que garante o funcionamento ótimo da economia. $\mathrm{O}$ ambiente dos anos 1920, sobretudo nos Estados Unidos, estava carregado desta convicção. Esta mesma convicção inundou a política, a academia e o mundo dos negócios a partir da guinada conservadora de Margaret Thatcher e Ronald Reagan. Os roaring twenties nos Estados Unidos culminaram com a Grande Depressão, e a euforia das finanças desregulamentadas culminou no desastre atual. A grande lição que resta destes dois episódios dramáticos é que, definitivamente, o capitalismo não pode ser deixado à mercê dos capitalistas...

FREDERICO MAZZUCCHELLI é professor do Instituto de Economia da Universidade Estadual de Campinas.
[16] Os dados sobre o desempenho econômico dos Estados Unidos, área do euro, Reino Unido e Japão no terceiro trimestre de 2008 já mostraram uma queda acentuada nos níveis de produção, de investimento, de comércio exterior e de emprego.

[17] Mandeville, Bernard. Fable of bees, or private vices, public benefits. 2 vols. Indianapolis: Liberty Fund, Ed. Liberty Classics, 1988 [1705].Ver, também, Dumont, Louis. Homo aequalis: gênese e plenitude da ideologia econômica. Bauru: EDUSC, 2000, cap. 5 .

Recebido para publicação em 20 de novembro de 2008. NOVOSESTUDOS CEBRAP

82 , novembro 2008 pp. 57-66 